\title{
A INTERDEPENDÊNCIA ENTRE DEMOCRACIA, BEM COMUM E DIREITOS HUMANOS: CONTRIBUIÇÕES JUSNATURALISTAS
}

\author{
THE INTERDEPENDENCE BETWEEN DEMOCRACY, COMMON GOOD
} AND HUMAN RIGHTS: NATURAL LAW CONTRIBUTIONS

Elden Borges Souza ${ }^{1}$ (i)

Victor Sales Pinheiro ${ }^{\mathrm{II}}$ (i)

\begin{abstract}
${ }^{\mathrm{I}}$ Universidade Federal do Pará (UFPA), Belém, PA, Brasil. Doutorando em Direito. E-mail: elden. borges@gmail.com
\end{abstract}

${ }^{\text {II } U n i v e r s i d a d e ~ F e d e r a l ~ d o ~}$ Pará (UFPA), Programa de Pós-Graduação em Direito da UFPA, Belém, PA, Brasil. Doutor em Direito. E-mail: vvspinheiro@yahoo.com.br

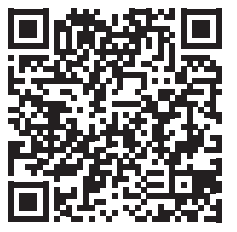

DOI: $10.20912 /$ rdc.v15i36.14

Recebido em: 15.02.2020

Aceito em: 03.04.2020
Resumo: A democracia é apresentada atualmente como o melhor modelo político e social. No entanto, os confrontos internos entre concepções morais contrapostas apresentam um desafio às visões liberais e utilitaristas de democracia. Afinal, na ausência de um critério moral para avaliar o fato democrático é impossível serem diferenciados governos que respeitam os direitos humanos e governos que os violam. Perde-se, assim, a compreensão do significado da democracia. Isso, por sua vez, afeta o conceito e a proteção dos direitos humanos. Destarte, esta pesquisa apresenta como hipótese a possibilidade de o bem comum aristotélico-tomista trazer contribuições à justificação moral das democracias contemporâneas e, a partir disso, aos direitos humanos. Analisando a teoria social tomista, é possível discutir em que medida o bem comum público permite compreender a finalidade e os limites da comunidade política e de seu governo. Consequentemente, a partir de uma concepção clássica de Direito Natural, questiona-se a possibilidade de o bem comum permitir a justificação do governo democrático em sociedades plurais, garantindo os direitos humanos de forma abrangente. A análise é por meio de uma revisão bibliográfica, baseando-se na discussão dos autores primários, como Aquino e John Finnis, e seus críticos liberais. Conclui-se pela necessidade de uma justificação da democracia baseada na ideia de persecução do bem de todos, o qual pode ser racionalmente identificado a partir da noção de bem comum político e viabilizará a garantia dos direitos humanos.

Palavras-chave: Democracia. Lei Natural. Direitos Humanos. Bem comum. 


\begin{abstract}
Democracy is presented as the best political and social model. However, internal clashes between opposing conceptions on moral present a challenge to the liberal and utilitarian views of democracy. After all, the absence of a moral criterion for assessing the democratic fact prevents a differentiation between governments that respect human rights and governments that violate them. We lose understanding of the meaning of democracy. This affects the concept and protection of human rights. Thus, the present Paper presents as hypothesis the possibility of the common good Aristotelian-Thomist bring contributions to the moral justification of contemporary democracies and, hence, to human rights. Analyzing Thomist social theory, it is possible to discuss to what extent the public common good allows to understand the purpose and limits of the political community and its government. Consequently, from a classical conception of Natural Law, the question is whether the common good allows the justification of democratic government in plural societies, guaranteeing human rights comprehensively. The research is by means of a bibliographical review, basing itself on the discussion of the primary authors such as Aquinas and Finnis, their liberal critics and the respective commentators. It concludes by the need for a justification of democracy based on the idea of pursuing the general well-being, which can be rationally identified from the notion of the political common good and will make it possible to guarantee human rights.
\end{abstract}

Keywords: Democracy. Natural Law. Human Rights. Common good.

\title{
Introdução
}

Ao se comparar a maioria das sociedades modernas com as sociedades antigas ou pré-modernas, é possível perceber que uma das grandes diferenças diz respeito à sua composição. Enquanto se poderia identificar nas cidades gregas e romanas e nas vilas medievais uma profunda ligação entre as pessoas - compartilhando a religião, a etnia, a concepção moral, a cosmovisão, entre outros elementos -, 
as sociedades contemporâneas são profundamente distintas entre si e, principalmente, em sua própria formação. As pessoas estão separadas por grandes abismos morais, religiosos, étnicos, nacionais e de visões de mundo.

Alguns sociólogos que se dedicaram a estudar a Modernidade perceberam essa mudança a partir da formação das cidades modernas, tipicamente cosmopolitas. Autores como Robert Park e Louis Wirth identificaram a cidade como um símbolo de todas essas mudanças. Para eles, a Modernidade não é apenas fruto dessa diferenciação dos indivíduos; ao contrário, parte do conceito do moderno está assentado em uma necessária perda da coesão social. Retomando sociólogos clássicos como Durkheim (1999) e Weber (1964), que distinguem a comunidade espiritual pré-moderna, marcada pela unidade religiosa da tradição, da sociedade comercial moderna, caracterizada pela diferenciação e fragmentação do indivíduo que se afirma independe do grupo social a que pertence, Park (1984) e Wirth (1938) apontaram que a sociedade moderna não apenas convive com a diferença, como, principalmente, incentiva aquilo que é diferente e excêntrico.

Nessa perspectiva, as sociedades modernas não teriam mais espaço para uma comunidade coesa, a qual está associada a uma baixa diferenciação entre seus membros. A Modernidade promove sociedades em que as relações entre seus membros são meramente funcionais e racionalizadas. A estabilidade social, portanto, não decorre mais do vínculo afetivo que a unidade de valores promovia entre os membros da comunidade pré-moderna. A cidade cosmopolita - representativa do período contemporâneo - está assentada sobre uma frágil estabilidade que decorre da diferenciação de funções e que faz surgir uma necessidade (acidental) do vínculo social (PARK, 1984; WIRTH, 1938).

Ao mesmo tempo em que se conclui isso, percebe-se a consolidação de uma concepção segundo a qual a democracia é o melhor regime político (SEN, 2010, p. 9). Em tal contexto, essa divergência moderna é vista como a grande causa do "fato democrático", que 
relaciona o fato social do pluralismo com a forma política da democracia (GOYARD-FABRE, 2003, p. 241). O paradoxo identificado ao serem confrontados esses dois fatos é que a democracia não pode funcionar adequadamente se as pessoas não compartilham nada de substancial. Isso gera conflitos insolúveis no seio da sociedade, impedindo decisões comuns e, consequentemente, impedindo a justificação moral do governo democrático.

Nesse sentido, o presente trabalho questiona a possibilidade de o bem comum aristotélico-tomista contribuir à justificação moral da democracia. Considerando esse bem comum como um ponto central da justificação moral do governo e critério para compatibilização dos bens particulares - grande desafio em sociedades plurais e não solucionado adequadamente pelas concepções liberais -, esta reflexão reinsere a noção de bem comum na concepção atual de democracia.

Tendo em vista o problema apresentado, este Artigo é teórico, voltando-se à leitura, análise e discussão dos autores primários e comentadores sobre os conceitos de democracia, direitos humanos e lei natural. Sendo assim, essa investigação está baseada em uma abordagem qualitativa do problema e pode ser considerada descritiva-explicativa quanto aos seus objetivos. Quanto ao método, o Artigo formula uma hipótese, cuja viabilidade será verificada enquanto resposta ao problema proposto. Portanto, adota-se o método hipotético-dedutivo.

O marco teórico do trabalho é a Teoria da Lei Natural. Por isso, enfatizam-se os autores que se inserem em tal tradição e seus críticos liberais. Realizar esse recorte metodológico é fundamental para viabilizar a síntese do argumento filosófico maior nos limites de um Artigo acadêmico, tendo em vista a diversidade de autores que buscaram retomar a concepção aristotélica de bem comum - e que nem sempre se inserem na tradição da lei natural. 


\section{Desafios e crises na democracia de índole liberal-procedimentalista}

Uma primeira forma de responder ao paradoxo de uma democracia sem comunidade - isto é, sem um vínculo substancial entre seus membros - é compreender a democracia em um sentido puramente formal, que reúne pessoas sem qualquer vínculo sob um mesmo ordenamento. Esse sentido formal foi o adotado em maior ou menor medida pelos liberais, pressupondo um certo grau de neutralidade ideológica dos cidadãos (GOYARD-FABRE, 2003). Ou seja, uma democracia despida de uma concepção moral substantiva a fim de garantir a liberdade individual e a autonomia pessoal (VITA, 2009).

Para essa alternativa, a relação entre a democracia e a moralidade é potencialmente antitética. Nesse contexto, a ética clássica de raiz aristotélico-tomista não conseguiria mais adequar seu pressuposto de objetividade do bem a uma sociedade plural, em que as pessoas divergem exatamente sobre a definição desse bem. Em outros termos, ainda que se fale em bem, em um contexto em que as pessoas se apresentam tão distantes, a divergência é inevitável. Por conseguinte, a democracia liberal seria o regime mais apto a permitir a tomada de decisões coletivas, por incluir todas as posições em um ambiente de neutralidade e tolerância.

No entanto, como Goyard-Fabre aponta, desde o século XIX, o crescimento e as transformações da democracia "fizeram dela um lugar de conflitos e de enfrentamento" (GOYARD-FABRE, 2003, p. 198), revelando exatamente a impossibilidade de uma neutralidade ideológica dos cidadãos. Isso é um problema, pois a democracia contemporânea não é uma questão apenas política, mas diz respeito, em especial, à sociedade. O risco decorrente desse conflito no seio da sociedade democrática é a adoção de uma democracia utilitarista (CHALMETA, 2002).

O problema central nessas justificações do governo democrático (que se afastam de concepções morais) é a sua incapacidade para 
fundamentar a legitimidade das decisões políticas (a lei e o exercício da coerção coletiva, principalmente) sobre as minorias e sobre aqueles que não participaram da decisão (os que não votaram, por exemplo). Para estes, a democracia não garante nem autogoverno, nem consentimento - principais justificações da democracia liberal. Ou seja, sua justificação pressuporia uma constante unanimidade sobre as decisões políticas, a qual é impossível, ou, caso fosse possível, tornaria o governo supérfluo (NINO, 2011, p. 302).

Aliás, o relativismo que pode acompanhar uma concepção democrática liberal - isto é, a tendência a contrapor a democracia à objetividade da verdade moral - é um risco ao próprio objetivo da democracia: conter a tirania. Como Popper (1974) destaca, uma concepção que negue a existência de um padrão moral além do que existe (a qual ele denomina de positivismo moral) impossibilita uma crítica moral do estado de coisas existentes. E isso tem uma implicação sobre o Direito. "A força é [ou torna-se] o direito" (POPPER, 1974, p. 218). Direito que deveria ser produto e, também, limite ao governo democrático. A democracia torna-se, então, incapaz de limitar o poder.

Por tudo isso, a democracia liberal passa por uma crise, principalmente quanto à fundamentação de suas decisões. É necessário, portanto, retomar algum conceito que permita justificar moralmente as decisões democráticas - em vez de critérios apenas formais ou quantitativos de cunho liberal ou de cunho utilitarista. Não se trata de procurar um modelo político alternativo, mas de analisar a justificação moral da democracia.

Nos termos da distinção metodológica feita pelo próprio Rawls (2008, p. 103), trata-se de considerar a democracia não como um caso de justiça procedimental pura - em que o próprio procedimento define a justiça do resultado, sem um critério independente, como em um caso de puro convencionalismo ou construtivismo ético -, nem de um caso de justiça procedimental perfeita - em que há um critério independente para definir o justo e o resultado do procedimento sempre será justo - e 
sim como um caso de justiça procedimental imperfeita - em que há uma noção de justo prévia ao procedimento, a qual não é necessariamente garantida por ele, como o oferecido pelo Jusnaturalismo Tomista

Defendida neste trabalho, a justiça procedimental imperfeita não nega a importância do procedimento para a formalização jurídica das relações sociais; o procedimento é causa necessária, mas não suficiente da realização da justiça. Ou seja, não haverá uma sociedade justa sem justiça procedimental, mas o procedimento, por si só, não garante a justiça, que o precede na sua dimensão substancial.

A questão posta no presente trabalho discute esse justo prévio ao procedimento - e que permite avaliá-lo - e a sua justificação moral.

\section{$2 \mathrm{O}$ risco de uma democracia autoritária e a necessidade de uma metaética realista}

Um dos debates mais intensos que vêm sendo experimentados no campo da Teoria do Direito nas últimas décadas (no caso do Brasil, nos últimos anos) decorre da retomada da Tradição Clássica da Lei Natural, denominada de Nova Teoria da Lei Natural. A publicação da obra "Lei Natural e Direitos Naturais", de John Finnis (2007), deu novo fôlego para os debates sobre a relação entre Direito, Moral e Política. Embora crescente, tal debate encontra-se longe de poder ser considerado esgotado.

No entanto, o atual debate sobre direito natural tem concentrado esforços no debate ético e na relação entre o Direito e a Moral - ao menos no Brasil -, muitas vezes negligenciando o debate acerca das instituições políticas ${ }^{1}$. Como consequência, reduz-se a relação entre Ética, Direito e Política nos diversos debates sobre as teorias da lei natural. Tal situação, no entanto, pode decorrer do fato de a retomada do jusnaturalismo (especialmente o clássico) no Brasil ser relativamente recente - principalmente por meio da recepção das obras de John

1 Sua relação com os direitos humanos tem sido um caminho para essa religação (PINHEIRO; SOUZA, 2016). 
Finnis $^{2}$. Em todo caso, um dos conceitos que a tradição clássica da lei natural pode introduzir nesse debate é o de bem comum.

Portanto, um dos aspectos que merece maior aprofundamento diz respeito ao papel do bem comum nessa teoria. Não apenas em Finnis, mas, especialmente, na tradição à qual ele pertence. É necessário rediscutir o lugar do bem comum aristotélico-tomista em sociedades plurais, como a contemporânea. Principalmente tendo em consideração que é por meio do conceito de bem comum que se torna possível relacionar Direito, Moral e Política. É por meio do bem comum político que são compreendidos os limites ao poder e, assim, o dever de garantia dos direitos humanos, por exemplo.

Por isso, partindo de uma discussão usual sobre a crise da democracia contemporânea, o presente trabalho analisa a democracia a partir de uma concepção ainda pouco discutida no Brasil - pelo menos sobre esse aspecto -, o Jusnaturalismo Clássico. Isso porque, a visão sobre a democracia que se consolidou no debate acadêmico nas últimas décadas foi a de uma democracia liberal. No entanto, esta parece não ser a única visão possível.

Desde o final da II Guerra Mundial, há uma percepção geral de que a democracia é o melhor regime político possível e que é dotado de uma espécie de superioridade moral (SEN, 2010, p. 9) ${ }^{3}$. Essas teses podem ser conjugadas à tese de que a democracia é o único caminho para lidar com o pluralismo. Isto é, a democracia é o modelo político mais legítimo em sociedades plurais (VITA, 2009). Mas essa tese não se encerra aí. Normalmente, associa-se o modelo democrático à impossibilidade de adoção de uma compreensão ética substancial. A democracia deveria, então, ser neutra a aspectos morais.

2 Com essa afirmação não se está ignorando a ampla produção de autores jusnaturalistas brasileiros, entre os quais se destaca José Pedro Galvão de Sousa (SOUSA, 1977).

3 A intenção de Carlos Nino ao tratar da democracia é comprovar essa superioridade (NINO, 2011). 
No entanto, se assim o for, não se tem a possibilidade de limitar e conter o exercício do poder democrático. As decisões democráticas tornar-se-iam sempre e automaticamente legítimas em razão do processo decisório. Essa é uma questão importante, pois, como ressalta Liniger-Goumaz (1984), atualmente, as ditaduras governam por meio de máscaras democráticas. Mesmo agindo com poder absoluto e de forma arbitrária e opressora, essas ditaduras participam da Organização das Nações Unidas e afirmam continuamente que são democracias como se isso, por si, as autorizasse e legitimasse.

Portanto, este Artigo, além de estar em um campo da Teoria do Direito em efervescente debate, também aponta para uma relação fundamental, entre Direito e Democracia - usualmente caracterizados pela relação entre Estado de Direito (rule of law) e Estado Democrático. A discussão a ser feita diz respeito a uma legitimidade democrática não puramente formal.

O presente trabalho parte, assim, de uma hipótese que problematiza eventuais críticas à possibilidade da objetividade do bem (e da verdade moral) em sociedades plurais. Uma vez que a tradição tomista da lei natural está assentada em um cognitivismo acentuado (FERREIRA NETO, 2015), o qual pressupõe uma realidade moral objetiva, usualmente se coloca tal concepção como relacionada a uma visão monolítica de bem, incompatível com o debate democrático e a pluralidade. $\mathrm{O}$ objetivo da pesquisa é problematizar essa crítica e, por outro lado, a discutir a possibilidade de determinação do bem por meio de um debate livre, racional, reflexivo e aberto - vantagem da democracia sobre outros modelos (NINO, 2011, p. 322).

A perspectiva proposta - ao assentar-se sobre um realismo ontológico e sobre um cognitivismo epistemológico - diferencia-se tanto de visões que baseiam a democracia em um convencionalismo ontológico - que negam a verdade moral em razão da diversidade de concepções morais -, quanto em um construtivismo epistemológico - que convive com o realismo ontológico, mas enfraquece-o no nível 
do cognitivismo (FERREIRA NETO, 2015, p. 141). Dessa forma, o presente Artigo procura compreender o debate democrático como um instrumento que possibilita o conhecimento da verdade moral (prévia e independente do procedimento) e não a sua construção - como as concepções dominantes defendem (NINO, 2011, p. 315).

Nesse sentido, segundo Millard (2008), o positivismo jurídico pretende ser a melhor forma de assegurar a democracia, pois parte de um não-cognitivismo ético e, segundo essa concepção, a democracia dependeria do relativismo ético. Ou seja, a democracia dependeria de uma base não-cognitivista. Em outros termos, "não há qualquer sentido em se falar em fatos morais ou verdades relevantes ao campo da ação humana" (FERREIRA NETO, 2015, p. 141), por isso elege-se um procedimento que considera todas as concepções morais em jogo como iguais e irredutíveis - incapazes de encontrar uma saída. Na expressão de Strauss:

Parecem acreditar que nossa incapacidade de adquirir algum conhecimento genuíno daquilo que é intrinsecamente bom ou correto nos obriga a ser tolerantes para com qualquer opinião sobre o bom e o correto, ou a reconhecer todas as preferências ou todas as civilizações como igualmente respeitáveis. Somente uma tolerância ilimitada seria conforme a razão (STRAUSS, 2014, p. 6).

Para Strauss, entre o direito natural e o cultivo irrefreado da individualidade, os liberais escolheram o último (STRAUSS, 2014, p. 7). O problema central é que a adesão à democracia depende de uma adesão a valores, como a autonomia, a igualdade e a dignidade da pessoa humana - talvez sua racionalidade (política) ${ }^{4}$. Isso tem implicação direta sobre a própria democracia e sobre o Direito - passando, obviamente, pela Moral.

O problema, então, é sobre como decidir entre uma tolerância que respeita a dignidade humana e uma tolerância que a viola. Uma

4 A solução talvez seja a adoção, pela democracia liberal, de um historicismo, de uma crença em uma lei histórica de progresso da sociedade que será manifesta por meio de decisões majoritárias (POPPER, 1974, p. 22). 
democracia baseada em um niilismo político dificilmente será capaz de perceber isso (STRAUSS, 2014, p. 7). É preciso tomar o caminho inverso de Maquiavel. É necessário reconciliar a política com a moral. E a hipótese deste trabalho é que o bem comum tomista é a base para isso $^{5}$.

A inclusão do bem comum é fundamental para dois pontos centrais na discussão sobre a justificação moral do governo democrático: sobre a necessidade do governo e sobre a colisão de bens particulares (NINO, 2011, p. 299). A necessidade de um sistema que assegure a justiça pública e a incapacidade de comunidades parciais asseguraremna colocam o bem comum público como a razão de ser dos governos. Por outro lado, a discussão sobre os limites aos bens particulares que os indivíduos estão obrigados a suportar pode ser calibrada a partir das exigências do bem comum - que, ao mesmo tempo em que protege o bem particular, estabelece um quadro dentro do qual certos limites razoáveis, claros e necessários são postos (FINNIS, 1998).

Nesse sentido, como expõe Rhonheimer (2013, p. 192), o Estado justifica sua atuação na promoção da cooperação social - superando os problemas de coordenação e os conflitos entre bens particulares - e na garantia da estabilidade das instituições políticas básicas por meio de razões públicas. Quando a Lei Natural integra essas razões públicas, o exercício do poder político passa a ser compreendido como não estando a serviço do seu próprio interesse, e sim a serviço do bem comum da totalidade dos cidadãos (RHONHEIMER, 2013, p. 194).

No entanto, vale destacar, a Lei Natural, dada sua amplitude, não se volta apenas à comunidade política. A Lei Natural possui também uma dimensão individual e uma dimensão social não política. Por isso, não é válida a crítica de que a participação da Lei Natural nas razões públicas implicará uma intervenção coercitiva (da lei ou das instituições políticas) indevida nos bens particulares - no projeto de

5 De forma ampla, a filosofia prática aristotélica e tomista nos possibilita tal unidade - sem eliminar a distinção entre moral e política (INICIARTE, 2001, p. 97). 
vida de cada pessoa. Embora a Lei Natural (em sentido amplo) tenha aplicação no âmbito pessoal, somente participa dessas razões públicas sua dimensão aberta ao entendimento em geral, politicamente relevante, e que necessite, razoavelmente, ser obrigado por meio da coerção da lei (RHONHEIMER, 2013, p. 192). Ou seja, seu elemento relacionado ao bem comum político.

Destarte, este Artigo retoma a ética clássica de cunho aristotélicotomista, superando uma visão equivocada de que tal concepção estaria presa em condições sociais e políticas do passado, carecendo de força intelectual para enfrentar os desafios contemporâneos. Por mais que a sociedade atual - pós-moderna, hipermoderna, de uma modernidade líquida ou tardia, conforme se denomine - seja radicalmente distinta das anteriores, isso não significa que o Tomismo não tenha mais possibilidades de indicar caminhos nos debates atuais.

Ademais, o direito natural não se limita à discussão sobre a separação ou não entre ética e direito, contrariamente ao positivismo. Trata-se de uma compreensão efetivamente transdisciplinar do Direito, percebendo-o em seus múltiplos aspectos. E é por meio dessa abrangência da Tradição da Lei Natural que as principais questões sobre a democracia podem ser compreendidas e analisadas.

\section{Compreendendo a concepção jusnaturalista de comunidade política e bem comum}

Um dos pontos centrais dessa investigação é a importância da comunidade para o indivíduo e, portanto, a centralidade do conceito de bem comum para o bem particular, que diz respeito a cada um, consoante a noção antropológica de pessoa humana como ser que se realiza em comunidade. Consequentemente, a relevância do bem comum para a garantia dos direitos humanos. A partir desse ponto é possível compreender a relevância e necessidade do governo e a possibilidade de harmonização entre os bens individuais. 
Um dos pontos fundamentais da ética tomista diz respeito à relação entre o individual e o comunitário. Uma interpretação distorcida do pensamento de Aquino pode levar à incorreta conclusão de que o interesse pessoal não tem qualquer relevância, ou que a comunidade é o único elemento importante na análise do bem. A questão assim posta decorre de um contexto em que o individualismo passou a ser considerado sinônimo de interesse pessoal e, dessa forma, totalmente legítimo. Por sua vez, a exigência de qualquer limite a um interesse individual em prol do bem-estar em comunidade passou a ser considerada presumidamente arbitrária.

Nesse contexto, a democracia deve apenas criar procedimentos por meio dos quais os bens particulares possam ser ponderados e, assim, haja uma decisão que os assegure sem limitá-los. Renunciase a um conceito de bem comum - ainda que relacionado aos bens particulares. No entanto, essa limitação sempre é necessária em razão dos problemas de coordenação usuais em qualquer sociedade. Além disso, mesmo nesse quadro, persiste o problema de justificar a decisão majoritária para a minoria que não considera que seu interesse tenha sido adequadamente tutelado por ela (NINO, 2011, p. 302). Isso é fundamental para vivermos em uma sociedade onde o direito de todos é assegurado.

Em primeiro lugar é necessário compreender a relevância da comunidade e, para isso, é necessário compreender que o conceito de indivíduo é diferente do conceito de pessoa. Indivíduo refere-se à separação de um ser em relação ao todo. É o ser humano considerado em si mesmo, enquanto matéria. A condição de pessoa, por sua vez, demanda a relação da parte (ou do indivíduo humano) com os outros. Esse elemento está intrinsecamente ligado a um dos bens que decorrem diretamente do aspecto social do ser humano: a comunidade (em sentido amplo). Ou seja, a interrelação humana não é acidental e, consequentemente, problemas de coordenação não são exceções (HERVADA, 2008, p. 315). 
Embora o ser humano tenha inclinações naturais naquilo que compartilha com os animais, a sua sociabilidade não se confunde com um simples impulso gregário que muitos animais possuem, não se resumindo a viver junto. Como afirma Aristóteles, mais que permitir viver juntos, a comunidade política tem por finalidade o viver bem (AQUINO, 2001, p. 273). A sociabilidade humana afeta uma dimensão corpórea, mas também uma dimensão intelectual - própria da pessoa humana. A pessoa realiza-se por meio de relações livres com outras pessoas, de forma que a comunidade é marcada por uma comunicação de ordem intelectual, que, nesse sentido, é própria do homem (HERVADA, 2008, p. 317). Por isso, inclusive, a verdade é considerada como um elemento fundamental, uma condição da comunidade em que seres racionais estão em relação (FINNIS, 1998, p. 154).

Essa interação humana não é irracional e nem está baseada em alguma concepção utilitarista que pondera vantagens e desvantagens. Ao contrário, tal sociabilidade tem por fundamento a amizade (de diversos níveis) e a busca por objetivos humanos comuns (HERVADA, 2008, p. 318). Assim, o social não é redutível ao individual (FINNIS, 1998, p. 24), como parece ser a posição de muitos liberais desde Hobbes, em que a comunidade é um mero acidente (HOBBES, 1993, p. 275$279)^{6}$. Esse parece ser também o posicionamento sobre a democracia contemporânea. Além disso, essa parece ser uma das causas de sua crise, em que o liberalismo de sua fundamentação acaba concretizandose politicamente por um método utilitarista (CHALMETA, 2002, p. 16).

Por outro lado, o individual não é redutível ao social. A singularidade da pessoa faz com que ela não seja redutível ao que existe de comum com as demais pessoas e nem permite que seja vista como apenas uma engrenagem no universo - como ocorre com as plantas e os animais (HERVADA, 2008, p. 304). A comunidade não é uma forma de engrenagem que absorve as ações individuais e acaba por promover

6 A natureza violenta do ser humana contraria essa posição em que o ser humano busca racionalmente, apesar das dificuldades, viver em comunidade. 
um organicismo totalitário. Essa ligação entre as pessoas negaria a fundamental dessemelhança existente entre cada uma delas, quer em sociedades marcadas por coesão social, quer em sociedades plurais.

Por outro lado, é possível falar em uma igualdade analógica da pessoa humana, a qual consiste na participação da mesma essência, daí a sua dignidade universal, mas com atualização existencial particularizada em cada experiência subjetiva, daí a liberdade individual. Em linguagem metafísica, pode-se dizer que toda atualização de uma forma universal se dá mediante acidentes que a particularizam. Por isso, nenhuma pessoa humana será univocamente idêntica a outra, e, exatamente por isso e não a despeito disso, todas têm a mesma dignidade essencial, a de realizarem livremente a natureza racional comum (BARZOTTO, 2010, p. 24). Sobre esses conceitos de igual dignidade (universal) e liberdade individual é que está assentada a noção de direitos humanos.

Dada a igualdade essencial e a relacionalidade da pessoa humana, várias comunidades podem se formar entre elas. No entanto, não se quer aqui tratar das comunidades de forma geral, mas especificamente da comunidade política. Segundo a interpretação de Aquino por Finnis (1998, p. 235), o indivíduo razoável - que age segundo a razão prática - quer viver com outros indivíduos dentro de uma comunidade política, considerando o auxílio que essa comunidade pode dar-lhe na busca de seus próprios objetivos (a felicidade imperfeita, no mínimo). E mais, para Aquino a lei, em seu sentido focal, depende de uma comunidade completa (civitas), envolvendo a noção de bem comum (FINNIS, 1998, p. 219). Portanto, é indispensável a relação entre Direito e Política, tendo em vista a relevância da comunidade política para a pessoa humana.

Énecessário, então, destacar que o conceito inicial de comunidade completa (civitas) em Aquino é formal, dizendo respeito a uma comunidade organizada de maneira que o seu governo e a sua lei dispõem coercitivamente todas as direções que podem ser propriamente dadas para promover e proteger o bem comum - que é o bem da comunidade 
e dos seus membros (FINNIS, 1998, p. 221-222)7. Nesse sentido, "o estado não é um organismo, mas uma ordem de agir cooperativo para algum propósito" (FINNIS, 1998, p. 242). Portanto, a noção de civitas não representa o Estado formado por instituições governamentais, e sim a sociedade de forma geral, organizada politicamente pelo governo e pela lei (FINNIS, 1998, p. 220) .

A primeira observação sobre tal conceito diz respeito ao propósito. Parece que a organização de qualquer comunidade sempre terá em consideração determinados propósitos, uma vez que não faz sentido falar de uma sociedade sem qualquer senso de finalidade. Se toda comunidade persegue algo, então toda comunidade tem alguma forma de bem - que pode ser assumido explicitamente ou negado. O propósito da comunidade política é assegurar a ordem, por meio da lei, para permitir o fim último da vida humana individualmente considerada, que é a felicidade ou bem-aventurança (beatitudo) - o que assegura, dessa forma, a felicidade comum (AQUINO, 2015, I-II, q. 90, a. 2). Trata-se do bem comum político, o qual fundamenta a sociedade (política) e, consequentemente, o governo e as leis humanas (FINNIS, 1998, p. 223).

Percebe-se, portanto, que a finalidade da comunidade política é indissociável da finalidade dos direitos humanos. Tomando por premissa que os direitos humanos asseguram a plena realização da pessoa humana (KAUFMANN, 2013, p. 54 e ss.), a comunidade política na busca do bem comum político direciona-se à garantia e promoção dos direitos humanos

É importante destacar que o bem comum que move o Estado é limitado, não sendo o único aspecto do bem comum existente. Ao contrário, Aquino defende que pessoas e outras comunidades (como

7 A definição assim coordenada é dada por Finnis, baseado em uma interpretação sistemática de algumas questões da Suma Teológica. Tal interpretação parece adequada à luz dos seguintes artigos da Suma Teológica: I-II, q. 90, a. 1 e a. 2, II-II, q. 65, a. 2, sol. 2 (AQUINO, 2015).

8 Por isso a referência à civitas será com “estado" em minúsculo. 
a família) possuem bens privados que não são relevantes para o bem comum político - embora sejam fundamentais para a plena realização humana - e que, portanto, não são passíveis de interferência da lei humana (em outras palavras, do direito positivo) e nem do governo (AQUINO, 2015, I-II, q. 96, a. 3). Encontra-se, portanto, um critério finalístico e limitativo do governo, seja ele de que espécie for - inclusive para o democrático.

Outro aspecto relevante da comunidade política é que, para Aquino, ela tem uma dimensão moral, uma vez que é constituída a partir de ações voluntárias (FINNIS, 1998, p. 26). Aliás, segundo Aquino, a comunidade política é a comunidade mais perfeita e o que de mais importante pode ser constituído pela razão humana, pois a ela se referem todas as comunidades humanas (AQUINO, 2001, p. 33-35). Outrossim, uma vez que não existe sociedade sem seus membros, não existe ação social sem ações individuais (FINNIS, 1998, p. 28), o que reforça sua dimensão de moralidade.

Sendo uma forma de relação racional, a comunidade é uma unidade de ordem, na qual os membros estão inter-relacionados de forma coordenada. E, principalmente, essa união e coordenação se dá em virtude da relação entre o grupo e o fim ou propósito da associação comum (FINNIS, 1998, p. 24) - e a promoção da busca por esses bens é papel da lei e do governo. A sociedade, como a pessoa, ordena-se para um fim e, para tanto, as pessoas coordenam-se entre si, para que, juntas, realizem o que sozinhas não poderiam alcançar, seja do ponto de vista substancial - como quando se unem em amizade -, seja do ponto de vista formal-instrumental - como quando garantem a ordem social e a paz pública, como condição de realização de bens substanciais como o conhecimento (AQUINO, 2015, I-II, q. 100, a. 6).

Tal coordenação é necessária pois, ao mesmo tempo em que as pessoas buscam determinados bens, esses bens não são passíveis de serem buscados apenas individualmente. Isto é, coordenam-se na busca de um bem não meramente individual. É assim que Aristóteles inaugura 
a Política, afirmando que o estado é formado a partir de alguma visão de bem (ARISTÓTELES, 1959, I, 1).

Portanto, juntamente com a comunidade exsurge a necessidade de busca e respeito ao bem comum. Dessa forma, a liberdade da pessoa em comunidade é uma liberdade que demanda a responsabilidade em relação ao bem da comunidade da qual participa (HERVADA, 2008, p. 315). Por isso, inclusive, para Aquino, o agir moral do homem depende de sua relação com a comunidade, uma vez que é impossível que alguém, que é parte da cidade, seja bom sem considerar o bem comum inclusivo ou abrangente - que não se confunde com o bem comum político ou público (da civitas), mas se relaciona com ele (AQUINO, 2015, I-II, q. 92, a. 1).

Destarte, na teoria social tomista o bem comum exerce um papel fundamental. Por um lado, a interrelação coordenada entre os diversos membros do grupo é essencial à ordem social. Por outro lado, tais pessoas precisam estar - enquanto grupo - relacionadas ao propósito ou finalidade da associação em comum e da coordenação que os torna um grupo. E esse objetivo é o critério de análise da interrelação entre os membros (FINNIS, 1998, p. 25) - permitindo valorá-la.

É, ainda, a existência desse fim na comunidade que permite a existência de relações inteligíveis entres as pessoas. Esses fins baseiam a coordenação da comunidade (FINNIS, 1998, p. 35). Dessa forma, como o fim pode acabar limitando a duração da coordenação (FINNIS, 1998, p. 36), a comunidade política não pode ter fins meramente temporários.

Nesse sentido, a finalidade do grupo é um elemento indispensável para a manutenção da ordem social - e da comunidade enquanto tal. Essa finalidade é indispensável para a realização do florescimento humano dos membros dessa ordem - considerando que esse é um dos elementos que sustenta a associação entre os indivíduos (FINNIS, 1998, p. 26). E esse objetivo pode ser identificado como o bem comum. No caso da comunidade política, o bem comum político ou público. Bem que 
possibilita a realização dos indivíduos, conserva a ordem social e, ao mesmo tempo, permite a crítica da interrelação existente.

De acordo com Aquino, quem busca o bem comum também busca seu próprio bem. Em primeiro lugar, pois o bem particular não pode existir sem o bem comum - seja de que comunidade for, da família à civitas. Em segundo lugar - e isso afasta qualquer tentativa de considerar o bem comum a partir de uma ótica utilitarista -, porque o homem faz parte da comunidade, de forma que precisa considerar o bem dessa comunidade, sob pena de seu desligamento do todo deformálo (AQUINO, 2015, II-II, q. 47, a. 10, sol. 2)9. Sendo cada pessoa parte de uma comunidade, como em uma relação entre as partes e o todo (AQUINO, 2015, II-II, q. 58, a. 5), os fins particulares - os bens das partes - participam do bem comum - o bem do todo - e são ordenados a ele pela lei enquanto causa final (AQUINO, 2015 , I-II, q. 90, a. 2).

Por isso, a grande oposição a essa construção de Aquino é a alegação contemporânea, especialmente de liberais, antropólogos e multiculturalistas, de que as opções baseadas na comunidade e no bem comum não são mais cabíveis. Afinal, não seria mais possível esperar um consenso constante na "comunidade" pós-moderna - que formam as sociedades pluralistas contemporâneas típicas. A concepção democrática atual pressupõe, em grande parte, essa tese.

A primeira tese dos críticos da concepção de comunidade e bem comum tomista é o denominado "fato do pluralismo" (VITA, 2009). Segundo eles, há uma diversidade irredutível na sociedade contemporânea e tal diversidade tem caráter normativo. Os seguidores dessa posição defendem, explícita ou implicitamente, que essa mudança decorreu da descoberta de certos fatos. Os antropólogos, por exemplo, mostram constantemente como as culturas diferem entre si e como,

9 Aquino é enfático ao afirmar que o bem particular (e, consequentemente, a realização individual) não pode ser buscado sem o bem comum (inclusivo e não apenas político). Fazendo referência a Agostinho, Aquino afirma que essa separação (ou não relação) entre a parte e o todo gera uma deformidade na parte. 
em uma mesma sociedade, as pessoas vivem de forma completamente diversa (GEERTZ, 2001, p. 49). Assim sintetiza Geertz (2001, p. 49): "não foi a teoria antropológica como tal que fez nosso campo de investigação parecer um argumento poderoso contra o absolutismo no pensamento, na moral e no juízo estético, mas sim os dados antropológicos".

O segundo achado antropológico foi o mais interessante: em uma mesma sociedade as formas de vida divergem profundamente. Liberais, então, afirmam que as pessoas vivem, em uma mesma sociedade, segundo concepções de vida boa complemente diversas e, principalmente, que essa controvérsia é insolúvel (VITA, 2009, p. 61). Ante um desacordo moral intransponível, não se tem outra opção senão acolher um modelo de instituições públicas e de decisões políticas que não encampem nenhuma concepção de vida boa. Por isso, tais críticos não aceitam a adoção de uma visão em que a comunidade possui um bem comum que baliza a busca de bens individuais pelos membros e em relação ao qual esses bens individuais precisam estar coordenados. No fundo, essa posição pressupõe a superação do bem comum por aquela excentricidade moderna indicada pelos autores da Escola de Chicago de Sociologia, referidos na Introdução deste artigo (WIRTH, 1938; PARK, 1984).

A segunda tese dos críticos, especialmente dos liberais, é que a coerção coletiva não pode ser usada para defender qualquer concepção de vida boa. E toda decisão política acaba sendo considerada um exercício coercitivo. Afinal, "qualquer decisão política, mesmo quando precedida por ampla discussão pública e tomada por meio do processo democrático, é sempre uma forma de emprego da coerção coletiva da sociedade" (VITA, 2009, p. 70). A resposta seria, defendem os liberais, a tolerância como virtude política.

Tal tolerância liberal diz respeito às decisões políticas fundamentais, sendo oposta às concepções perfeccionistas (RAWLS, 
$2008)^{10}$, como a de Aquino, nas quais determinada ideia de bem - acerca dos fins da comunidade - direciona a autoridade e guia as decisões políticas - o governo e a lei, para usar o vocabulário tomista. A coerção coletiva não poderia estar disponível ao segundo tipo de concepção, pois o poder político não pode aderir a uma determinada concepção de vida boa. Por essa via, seria assegurada a igualdade e autonomia privada e política dos indivíduos a respeito dessas doutrinas abrangentes de bem (VITA, 2009, p. 66).

Percebe-se, então, como Direito e Democracia acabam intimamente relacionados: (i) Não podendo a comunidade política estar associada a uma concepção de bem, (ii) a democracia também não deve ser afetada por concepções de bem. Sendo assim, (iii) o direito é produto da política (embora não apenas dela) e, por isso, (iv) não pode refletir uma concepção de bem. (v) O problema é que isso retira as possibilidades de limitação finalística do Direito e da Democracia. Essas cinco premissas encontram-se intimamente relacionadas.

Destarte, tais posições desconsideram pontos fundamentais apontados por Aquino a respeito da comunidade política e do bem comum. De início, embora possa ser negado no discurso, sem essa finalidade comum, a comunidade se dissolve ou perde completamente a legitimidade para exercer a coerção. Sem uma unanimidade universal (isto é, de todos os destinatários de uma decisão política) é difícil fundamentar o exercício da coerção pela democracia (NINO, 2011, p. 304). A menos que seja a força e a vontade da maioria, independentemente de qualquer critério de legitimação. Nesse caso, não se tem como diferenciar substancialmente a democracia dos demais modelos (NINO, 2011, p. 307) - nem mesmo de uma tirania.

Ademais, Aquino não trabalha com a ideia de uma comunidade política perfeita, onde todos concordam. Ao contrário, na posição tomista, mesmo que todos os homens fossem bons e inteligentes (uma

10 John Rawls deixa clara sua oposição ao perfeccionismo logo no primeiro capítulo de sua obra clássica, "Uma teoria da justiça". 
sociedade de anjos, como normalmente é referida tal hipótese), haveria divergência sobre como agir, demandando um elemento que assegurasse a unidade da ação social em direção ao bem comum inclusivo (FINNIS, 1998, p. 248). Portanto, com muito mais razão, na comunidade política real é necessária uma política pública determinada e feita conhecida pelo direito da comunidade e por sua autoridade (FINNIS, 1998, p. 36). Como já dito, parece que a democracia é o melhor instrumento para essa coordenação de agentes por propiciar um debate livre e racional, já que, na explicação de Finnis sobre Aquino:

o caso central do governo político é o governo de um povo livre, e o caso central do direito é o da coordenação de sujeitos voluntários por um direito que, pelo seu caráter público (promulgado), sua claridade e generalidade, estabilidade e praticalidade, trata aos sujeitos como participantes da razão pública (FINNIS, 1998, p. 257).

As críticas antropológicas e liberais costumam ignorar, ainda, que o bem comum político não se confunde com o bem comum inclusivo, sendo limitado e instrumental e fundamento da legitimidade do governo e das leis. Aquino faz claramente essa delimitação quando utiliza a expressão "bem público" ou "bem comum político", fazendo referência a bens intrinsecamente interpessoais, direcionados aos outros, de pessoa para pessoa. Isto é, o bem quando relacionado à paz e à justiça. Isso significa, por um lado, que a lei - em sentido amplo - preocupa-se com a amizade entre as pessoas, e não apenas com eventuais faltas de concordância. No entanto, a lei humana tem apenas o objetivo limitado de assegurar as condições de paz necessárias ao gozo dos benefícios da vida em sociedade e evitar o ônus da discórdia, de forma que vícios sem relação significativa, direta ou indireta, com a justiça e a paz não são uma preocupação do governo ou da lei. Por isso, a lei humana não tem a pretensão de - e nem deve tentar - coibir todos os vícios (AQUINO, 2015, I-II, q. 96, a. 2). Ela é limitada pela própria liberdade racional e autenticidade pessoal de cada um em escolher o seu plano de vida, conforme o horizonte social do bem comum. 
Isso leva a perquirir o papel da civitas e sua relação com o bem no pensamento de Aquino. Nesse sentido, a civitas pode ser chamada "natural", se a participação nela (i) instancia em si mesma um bem humano básico; ou (ii) é um componente racionalmente exigido em um ou mais bens humanos básicos - ou um meio indispensável para instanciá-los. Segundo Finnis, Aquino segue a segunda posição - e esta leitura parece ser a mais adequada (FINNIS, 1998, p. 246) ${ }^{11}$.

Tal afirmação decorre da interpretação segundo a qual indivíduos e famílias poderiam instanciar todos os bens humanos básicos, pelo que a comunidade política não tem um bem humano básico próprio (FINNIS, 1998, p. 247). A afirmação, portanto, de que não se pode viver de forma razoável e boa aparatados da civitas decorre da compreensão do bem público como instrumental para assegurar bens humanos básicos - os quais não concernem à civitas (FINNIS, 1998, p. 245).

A incompletude, então, que demanda essa instrumentalidade refere-se à inabilidade de indivíduos e comunidades menores a (i) assegurar-se contra agressões; e (ii) manter um sistema justo e estável de distribuição, exploração e troca dos recursos - que são naturalmente aspectos do bem comum. Indivíduos e famílias não conseguem assegurar adequadamente, nem manter os elementos que formam o bem público da justiça e da paz. Assim, a instanciação dos bens por indivíduos e famílias é menos segura e plena do que poderia ser se a justiça e paz públicas fossem mantidas por meio da lei e do governo - o que eles não podem fazer sozinhos (FINNIS, 1998, p. 249).

Pessoas e comunidades menores não estão equipadas para julgar conforme uma lei publicamente estabelecida e não podem impor medidas irreparáveis necessárias à restauração da justiça e da paz. São incompletas (imperfecta) e necessitam ser complementadas por uma ordem de justiça pública (perfecta). Como pessoas privadas não são 
juízes, não podem impor medidas irreparáveis de justiça (FINNIS, 1998, p. 251).

Sendo assim, é possível compreender que para Aquino o bem público ou político funciona como justificação das instituições políticas, as quais devem identificá-lo e promovê-lo em suas comunidades políticas. Consequentemente, essa responsabilidade pelo florescimento humano não pode ser transferida a pessoas ou grupos que não as instituições (FINNIS, 1998, p. 132). E, ao mesmo tempo, tal responsabilidade é limitada e precisa deixar famílias e indivíduos também responsáveis por esse bem, independente do governo e da lei. Isso significa que o bem relacionado à lei e ao governo não elimina as demais responsabilidades (FINNIS, 1998, p. 242).

Tal limitação é conclusão da compreensão sobre o que a comunidade política (por meio de seu governo e lei) pode e não pode contribuir para a felicidade dos seus membros. Assim fica delimitado o bem comum político. Principalmente considerando que indivíduos, famílias e comunidades menores não são redutíveis à comunidade política ou ao bem público. Ao contrário, o bem comum político apenas suplementa, serve e supervisiona os aspectos privados. É a partir disso que se compreende o princípio da subsidiariedade, segundo o qual, salvo exceções, é contrário às características do governo que ele impeça as pessoas de agirem conforme suas responsabilidades (FINNIS, 1998, p. 237).

Dessa forma, juízes e legisladores possuem autoridade e responsabilidade limitadas. Estão limitados aos atos que afetam o bem comum da comunidade - conforme os critérios de paz e justiça -, uma vez que tais atos importam aos demais e, em consequência, importam à lei e ao governo. Embora pareça óbvio, é preciso pontuar que essa afetação é exterior, que atos internos não estão sob a autoridade política. Logo, eles são responsáveis por assegurar apenas esse bem comum político externamente e somente nos limites desse bem eles podem exigir o respeito e o apoio das pessoas. 
Assim, torna-se possível falar de critérios para julgar um governo democrático, que não se reduzem apenas à sua forma procedimental. Usando a metodologia de Finnis (FINNIS, 2007, p. 23), é possível falar em um significado focal de democracia, a qual manifesta o sentido de racionalidade e finalidade presentes no bem comum. Por meio do bem da comunidade as decisões democráticas encontram fundamentação e conferem legitimidade ao uso da coerção coletiva. Uma das principais formas de a democracia manifestar esse bem comum está na preservação dos direitos humanos.

\section{Democracia: a sua justificação a partir do bem comum e dos direitos humanos}

Um dos maiores desafios à fundamentação - ou formulação - do conceito de direitos humanos a partir do bem comum é a desconstrução de uma imagem individualista defendida aberta ou implicitamente. A sociabilidade humana e a comunidade são conceitos extremamente importantes em Aquino. Por isso, a fundamentação a partir dele impõe fugir do individualismo, permitindo formar uma tradição de direitos que consiga coordenar individualidade e comunidade, liberdade e responsabilidade.

Os direitos humanos contemporâneos são - ressalvadas algumas tentativas de consideração comunitária - direitos baseados claramente na virada copernicana promovida por Hobbes (1993). Essa revolução conceitual mudou a noção de direitos, afastando a noção de dever e migrando a concepção de direito para um conceito de poder - em uma clara direção nominalista (DOUZINAS, 2009, p. 83). E, principalmente, retirou o homem e seus direitos do seio comunitário.

A partir dessa posição, a coletividade humana é sempre um risco ao indivíduo - não mais pessoa, porque afastado do atributo social desta -, tendo em vista uma natureza humana altamente violenta. Em consequência, a comunidade não é mais o lugar de realização e florescimento humano. Trata-se de um acidente, algo que 
é contingencialmente necessário. Não há algo semelhante a um bem a guiar a finalidade da comunidade. Essa reunião de seres humanos existe apenas para garantir o mínimo de segurança para que cada pessoa possa buscar seus próprios objetivos - não mais bens, necessariamente, uma vez que podem ser apenas paixões ou prazeres - o que abre as portas para o utilitarismo (DOUZINAS, 2009, p. 85).

Não se pode falar, na verdade, em uma comunidade, pois trata-se apenas de uma reunião de indivíduos, sem qualquer laço que os ligue, pois essa seria a função do bem comum, que é especialmente rejeitado. Nesse sentido, os direitos enquanto poderes servem exatamente para garantir um espaço de liberdade a um homem que, por sua natureza, é lobo do outro homem (HOBBES, 1993, p. 275).

A ausência de deveres, por outro lado, garante uma sociedade individualista, em que ninguém tem a obrigação de preocupar-se com o outro. Não há mais, nesse sentido, a ideia de relação, de empatia, de um dever de considerar o próximo como um igual, titular de direitos e deveres em uma relação comigo. Aliás, o outro é um igual, sim, em força, por isso deve ser temido e, por isso, é necessária essa coletividade. Não porque o indivíduo deva reunir-se com o outro para buscar um bem que os realize, mas porque os demais são potenciais inimigos, capazes de impedir a busca pelos objetivos e paixões individuais.

No entanto, lembra Durkheim, esse não é o único tipo de individualismo. Ao contrário, embora ainda exista essa concepção, em que a sociedade é apenas um vasto aparelho de produção e troca, sem qualquer interesse superior, trata-se de uma visão de individualismo mais frágil e que tende a tornar-se uma raridade - assentada em um individualismo utilitário: "Na verdade, se o individualismo não tivesse outros representantes, seria inútil fazer um alarido para combater um inimigo que está morrendo tranquilamente de morte natural" (DURKHEIM, 2007, p. 299).

Segundo Durkheim, o individualismo dos direitos humanos pelo menos aquele das declarações de direitos - é um pouco diferente. 
E foi esse individualismo que "se tornou a base de nossa catequese moral" (DURKHEIM, 2007, p. 300). Segundo essa visão, o interesse pessoal é a fonte do mal e não deve ser o critério do agir moral. Para esse tipo de individualismo o agir moral é aquele que pode convir a todos os homens indistintamente - ao homem em geral. Por isso, é um individualismo não do indivíduo particular com seus interesses, mas do indivíduo em geral, fora da sociedade (DURKHEIM, 2007, p. 309). Por meio desse mecanismo de abstração, embora mais elaborado que o anterior, essa forma de individualismo continua tendo um problema com o papel da sociedade (ou comunidade) para o indivíduo.

Segundo Barzotto (2010, p. 49), esse idealismo seria uma das formas modernas de antropologia que reduz o ser humano a uma abstração universalista, independente das suas experiências históricas.

O outro reducionismo moderno seria o empirismo, que contribui para o individualismo - e, consequentemente, para o caráter liberal - dos direitos humanos. Trata-se da constatação empírica de que as sociedades não são perfeitas ou ideais e que as pessoas que formam essas sociedades são diferentes. Constata-se uma variação profunda entre as sociedades e dentro delas, de forma que não se encontram tradições e práticas incólumes em relação às variações individuais (DURKHEIM, 2007, p. 306). Isso, em tese, aponta para a conclusão de que não há nada além da individualidade dos sujeitos, o que, contudo, é um problema para o conceito de direitos humanos em sua dimensão social, pois eles passam a ser tomados como armas individuais em uma guerra de todos contra todos (GLENDON, 1991).

Por essa lógica individualista, a política é uma prática limitada à realidade das contingências. Da mesma forma, a justiça não pode mais fazer referência a algum tipo de padrão substancial, trata-se tão somente de um conceito formal que significa: obedecer às leis e cumprir as promessas. No entanto, o conceito de direitos humanos traz consigo um objetivo não passível de satisfação por essa concepção - quer na 
versão autoritária de Hobbes, quer nas versões mais democráticas de Locke e Rousseau.

Em primeiro lugar, os direitos humanos estão necessariamente relacionados a uma ideia de justiça - nos moldes de Aquino. Não em um sentido utópico - como algumas interpretações tendem a adotar, como a de Douzinas (2009) -, mas enquanto relação em que o devido é respeitado - principalmente o devido (o justo) por natureza, que não depende de uma norma positiva para estar na condição de coisa devida a alguém (BARZOTTO, 2010, p. 43).

No entanto, a justiça não é algo que se realize individualmente, ao contrário, o lócus da justiça é a comunidade. Nesse sentido, os direitos humanos não podem ser vistos como o poder para o isolamento dos indivíduos, mas, principalmente, como um instrumento de mudança das relações sociais na busca da realização possível do justo - tanto na justiça geral, quanto na justiça particular. Para tanto, é necessária a retomada da concepção de justiça tomista, em que a justiça é uma forma de amizade, a cooperação na busca do bem do outro - e que, de alguma forma, realiza o bem individual (BARZOTTO, 2010, p. 116).

Essa concepção de justiça é oposta à proposta do liberalismo, para quem não há comunidade, mas tão somente uma reunião de indivíduos entre os quais não há nada compartilhado e nem finalidade comum. Somente nessa teia de relações sociais o ser humano tem garantido o mais básico que lhe é devido, podendo realizar-se. Isso porque a justiça em Aquino não é apenas a particular - de pessoa para pessoa. Ao contrário, ela envolve uma relação com a comunidade, em que o indivíduo tem deveres para a busca do bem comum e, ao mesmo tempo, a comunidade tem deveres para com o indivíduo, que colaboram e permitem a busca e realização de seus bens particulares (BARZOTTO, 2010, p. 91).

Nesse sentido, o bem comum é objeto da justiça - no caso, da justiça geral. E esse bem inclui intrinsicamente tanto os bens individuais quanto os bens comuns de comunidades menores - em relação à civitas . 
Por isso, o respeito e a promoção do bem comum depende do respeito e da promoção dos direitos e vice-versa. Não se trata de uma via de mão única em nenhuma das direções. $O$ vínculo comunitário depende e existe para promover esse respeito por direitos. Bem individual e bem comum não são, portanto, opostos e não estão necessária e indissoluvelmente em conflito (FINNIS, 1998, p. 133).

Por meio de Aquino é possível fundamentar uma concepção de direitos humanos que supera o individualismo ao reconhecer que o ser humano é, ao mesmo tempo, um ser individual e social. O homem somente pode ser plenificado em comunidade, em que existe bem e finalidade - não em uma reunião voluntária e meramente contratual de pessoas, como propõe a sociedade liberal (FINNIS, 1998, p. 121). A democracia, então, tem um papel fundamental de realizar os bens humanos básicos, por meio da persecução do bem comum. Isso envolve um compromisso com os direitos humanos que não pode ser suplantado pela vontade da maioria. Como esses direitos são o fundamento da democracia, eles estão, em regra, excluídos do procedimento democrático (NINO, 2011, p. 324).

Isso não significa, contudo, uma forma de organicismo ou coletivismo, que ignora a individualidade da pessoa. Afinal, é contraditório pensar em pessoa e ignorar sua personalidade. A posição de Aquino é no sentido de que o bem individual é importante - ele não defende uma forma de altruísmo, em que se pressupõe a renúncia a todos os interesses pessoais. No entanto, esse bem individual somente pode ser realizado a partir da comunidade. Portanto, sendo os direitos humanos a garantia da condição de pessoa, eles precisam necessariamente reconhecer a dimensão comunitária do ser humano e dependem de instituições políticas.

a pessoa está em sociedade como pessoa, não como simples indivíduo, isto é, não se funde no todo social como simples parte dele ou como simples peça da engrenagem social. A dimensão social é uma dimensão da pessoa humana, que não 
a abrange totalmente. A pessoa permanece como ser autônomo (HERVADA, 2008, p. 307).

Nesse sentido, mesmo em comunidade o ser humano permanece livre e, portanto, dotado de dignidade. Não são ideias opostas. Tratase de uma dignidade que se realiza em uma teia de relações humanas exatamente porque o ser humano realiza-se socialmente. Por isso, não faz sentido defender por meio dos direitos humanos os aspectos mais essenciais da pessoa humana - entre os quais, a sociabilidade - partindo de um individualismo em que todos são inimigos públicos mútuos e em que a sociedade não tem limites (sendo basicamente uma manifestação de uma vontade de poder). Assim, "pode-se perceber que a concepção liberal primitiva do homem, como indivíduo absoluto, associal em estado natural, cai por terra. Basta observar que falavam de indivíduo, não de pessoa" (HERVADA, 2008, p. 306).

\section{Conclusão}

A democracia contemporânea não é a mesma coisa que a democracia grega (ou, de forma mais geral, dos antigos). As mudanças pelas quais passou a sociedade atual afetaram diretamente a justificação dessa democracia, cujo conceito adotado passou a ser de base liberal - para supostamente atender ao fato do pluralismo, isto é, a tese de inexistência de um bem da comunidade política. No entanto, como visto, a consequência prática deste conceito não dista de uma concepção utilitária de democracia. Como consequência, o governo democrático não consegue se justificar perante minorias e grupos que não participaram da votação, sendo, além disso, incapaz de conter a potencial tirania de grupos majoritários contra minorias.

A proposta apresentada neste trabalho é de que o bem comum tomista possibilita a fundamentação do governo democrático a partir da identificação de uma finalidade na comunidade política. Consequentemente, existe uma justificação moral do governo e, mais 
que isso, de um governo baseado em um procedimento aberto que permita racionalmente a identificação do bem comum.

Os limites desse governo democrático são o caráter instrumental do bem comum político, limitado pela garantia de bens humanos básicos. Ou seja, a democracia não é meramente formal, mas adquire uma dimensão substantiva e não-convencional - objetiva, portanto. Em suma, segundo a Teoria da Lei Natural, um governo democrático não se justifica de modo autorreferente, mas sim a partir de conceitos objetivamente cognoscíveis.

Por fim, vale ressaltar, a hipótese da interrelação entre democracia, direitos humanos e bem comum não busca a retomada de algum tipo de unidade passada - e nem depende disto -, em que as pessoas possuíam vínculos profundos entre si. Uma retomada pré-moderna. Uma tentativa assim, "desejável ou não, ultrapassa infinitamente todas as forças humanas" (DURKHEIM, 2007, p. 307). No entanto, depende do reconhecimento de atributos comuns à pessoa humana, que a tornam inviolável, entre os quais a individualidade e a sociabilidade. Da mesma forma, depende do reconhecimento da importância da comunidade e do bem comum para a realização da pessoa humana. Ambos, como um novo paradigma para compreender o "fato democrático".

Somente por meio de uma comunidade política limitada por um bem comum público e voltada à garantia da paz e da justiça consequentemente, promotora e garantidora dos bens individuais -, a condição de pessoa pode ser reconhecida e protegida. E somente assim poderemos compreender a fundamentação e a legitimidade do governo democrático.

\section{Referências}

AQUINO, Tomás de. Comentario a la Politica de Aristóteles. Pamplona: EUNSA, 2001. 
AQUINO, Tomás de. Suma contra os gentios. Vol. I-II. Porto Alegre: Escola Superior de Teologia São Lourenço de Brindes, 1990.

AQUINO, Tomás de. Suma Teológica. Vol. I-VII. 3. ed. São Paulo: Edições Loyola, 2015.

ARISTÓTELES. Politics. Cambridge: Harvard University Press, 1959.

BARZOTTO, Luís Fernando. A Democracia na Constituição. São Leopoldo: UNISINOS, 2003.

BARZOTTO, Luís Fernando. Filosofia do direito: os conceitos fundamentais e a tradição jusnaturalista. Porto Alegre: Livraria do Advogado, 2010.

CHALMETA, Gabriel. La justicia política en Tomás de Aquino: una interpretación del bien común político. Pamplona: EUNSA, 2002.

DAHL, Robert A. A preface to democratic theory. Chicago: The University of Chicago Press, 2006.

DAHL, Robert A. On democracy. New Haven: Yale University Press, 1998.

DOUZINAS, Costas. O Fim dos Direitos Humanos. São Leopoldo: UNISINOS, 2009.

DURKHEIM, Émile. Da divisão do trabalho social. 2. ed. São Paulo: Martins Fontes, 1999.

DURKHEIM, Émile. O individualismo e os intelectuais. Revista de Direito do Cesusc, Florianópolis, n. 2, p. 299-311, jan./jun. 2007.

FERREIRA NETO, Arthur Maria. Metaética e a fundamentação do direito. Porto Alegre: Elegantia Juris, 2015.

FINNIS, John. Aquinas: Moral, Political and Legal Theory. Oxford: Oxford University Press, 1998.

FINNIS, John. Is natural law theory compatible with limited government? In: GEORGE, Robert P. (ed.). Natural law, Liberalism, and morality. Oxford: Clarendon Press, 1996, p. 1-26. 
FINNIS, John. Lei natural e direitos naturais. São Leopoldo: UNISINOS, 2007 [1980].

GEERTZ, Clifford. Nova Luz sobre a Antropologia. Rio de Janeiro: Jorge Zahar, 2001.

GEORGE, Robert P. In Defense of Natural Law. Oxford: Oxford University Press, 2004.

GEORGE, Robert P. Making Men Moral: civil liberties and public morality. Oxford: Clarendon Press, 2002.

GLENDON, Mary Ann. Rights Talk: the impoverishment of political discourse. Nova York: The Free Press, 1991.

GOYARD-FABRE, Simone. O que é democracia? A genealogia filosófica de uma grande aventura humana. São Paulo: Martins Fontes, 2003.

HERVADA, Javier. Lições propedêuticas de filosofia do direito. São Paulo: WMF Martins Fontes, 2008.

HOBBES, Thomas. De Cive: elementos filosóficos a respeito do cidadão. Petrópolis: Vozes, 1993.

INICIARTE, Fernando. Liberalismo y republicanismo: ensayos de filosofía política. Pamplona: EUNSA, 2001.

KAUFMANN, Matthias. Em defesa dos direitos humanos: considerações históricas e de princípio. São Leopoldo, 2013.

LINIGER-GOUMAZ, Max. ONU et dictadures: de la démocratie et des droits de l'homme. Paris: Editions L'Harmattan, 1984.

MILLARD, Eric. Positivismo y derechos humanos. Revista Juridica (Faculdad de Derecho Universidad Nacional de Mar del Plata), Buenos Aires, ano 3, n. 3, p.329-340, 2008.

NINO, Carlos Santiago. Ética e direitos humanos. São Leopoldo: UNISINOS, 2011.

NUSSBAUM, Martha C. Aristotelian Social Democracy. In: DOUGLASS, R. Bruce; MARA, Gerald M.; RICHARDSON, Henry 
S. (ed.). Liberalism and the Good. Londres: Routledge, 1990, p. 203-252.

PARK, Robert E. The City: Suggestions for the Investigation of Human Behavior in the Urban Environment. In: PARK, Robert E.; BURGESS, Ernest W (org.). The City: Suggestions for the Investigation of Human Behavior in the Urban Environment. Chicago: The University of Chicago Press, 1984 [1925].

PERRY, Michael J. A Global Political Morality: Human Rights, Democracy, and Constitutionalism. Cambridge: Cambridge University Press, 2017.

PINHEIRO, Victor Sales; SOUZA, Elden Borges. A fundamentação ética dos direitos humanos em John Finnis. Revista Direitos Humanos e Democracia, Ijuí, ano 4, n. 7, p. 65-83, jan./jun. 2016.

POPPER, Karl R. A sociedade aberta e seus inimigos. Vol. 1-2. São Paulo: Editora da Universidade de São Paulo, 1974.

RAWLS, John. Justiça e democracia. São Paulo: Martins Fontes, 2000a.

RAWLS, John. O liberalismo politico. 2. ed. São Paulo: Editora Ática, 2000 b.

RAWLS, John. Uma teoria da justiça. 3. ed. São Paulo: Martins Fontes, 2008.

RHONHEIMER, Martin. The Common Good of Constitutional Democracy. Washington D.C.: The Catholic University of America Press, 2013.

SEN, Amartya. Desenvolvimento como liberdade. São Paulo: Companhia das Letras, 2010.

SOUSA, José Pedro Galvão de. Direito Natural, Direito Positivo e Estado de Direito. São Paulo: Revista dos Tribunais, 1977.

STRAUSS, Leo. Direito Natural e História. São Paulo: WMF Martins Fontes, 2014.

VITA, Álvaro de. Sociedade Democrática e tolerância liberal. Novos estudos (CEBRAP), São Paulo, v. 84, p. 61-81, jul. 2009. 
A Interdependência entre Democracia, Bem Comum e Direitos Humanos... Elden Borges Souza | Victor Sales Pinheiro

WEBER, Max. Economía y sociedad: esbozo de sociología comprensiva. 4. ed. México: Fondo de Cultura Económica, 1964.

WIRTH, Louis. Urbanism as a Way of Life. The American Journal of Sociology, Chicago, vol. 44, n. 1. p. 1-24, Jul. 1938. 